\title{
EL CONFLICTO COMO ESPACIO DE CONFUSIÓN DE ELEMENTOS SEMIÓTICOS
}

\section{CONFLICT AS A SPACE OF CONFUSION BETWEEN SEMIOTIC ELEMENTS}

\section{Miguel MARTÍN ECHARRI}

\author{
Universidad de Burgos \\ mmecharri@ubu.es
}

\begin{abstract}
Resumen: Este trabajo ofrece un panorama de posibilidades semióticas para el estudio y análisis del engaño en el ámbito del conflicto, ejemplo de la fragilidad y versatilidad de los códigos cuando desaparece la cooperación. En la semiosfera, la no cooperación puede provocar que cada uno de los elementos de la comunicación modifique su función o participe de varias simultáneamente, en una forma de subversión sistemática. A partir de la intensa codificación de la diplomacia y la violencia, un sujeto interesado puede usar la desinformación para involucrar al enemigo en un modelo comunicativo fingido.
\end{abstract}

Palabras clave: Semiótica de la guerra. Conflicto. Comunicación. Elementos de la comunicación.

Abstract: We offer a panorama of semiotic possibilities for the study and analysis of deception in the domain of conflict, example of the frailty and versatility of codes when cooperation disappears. In the semiosphere, non- 
cooperation can make any of the elements of comunication modify its functions or participate simultaneously in many, in a kind of systematic subversion. On the basis of the intense codification of violence and diplomacy, a biased subject can use disinformation to involve his enemy in a faked communicative model.

Key Words: Semiotic of war. Conflict. Communication. Elements of communication.

\section{INTRODUCCIÓN}

En el ámbito de los conflictos, a menudo se ha imaginado la posibilidad ideal de un contendiente capaz de tomar en todo momento la decisión más acertada, "maqueida" (Lasker, 2003: 38), pero se olvida que sus conocimientos pueden ser engañados o traicionados por el enemigo. Lasker parece tener en cuenta ante todo los juegos (con normas inviolables), dentro de cuyo código cobra sentido la alternativa "eumáquica": puede pensarse en una acción militar óptima siempre que conozcamos efectivamente todas las circunstancias o que las limitemos hasta lo que efectivamente podemos conocer. Pero esto es ingenuo si nos enfrentamos a un enemigo que está dispuesto a traicionar los acuerdos o a introducir dispositivos que nos sean desconocidos. Así que el sistema que manejamos en nuestra pretensión de llevar a cabo la acción eumáquica es un conjunto de convicciones culturales que en un momento dado puede convertirse en nuestro peor enemigo.

Muchos autores han desarrollado las posibilidades semióticas de las relaciones conflictivas. Greimas y Courtés (1979: 284) se centran en el principio polémico como constante en el imaginario humano y en la organización narrativa de los discursos, pero también como principio rector de las actitudes en el nivel de la enunciación, es decir, en el entorno de la estructura de la comunicación intersubjetiva, desde la obediencia al 
chantaje.

Fabbri desarrolla la particular relación entre enemigos, obligados a entenderse hasta un punto que es infrecuente en las relaciones de cooperación. Si en estas basta con compartir un ámbito con el otro, la guerra obliga a explorar el mundo del adversario como fuente de informaciones potencialmente decisivas. En un acercamiento a la zoosemiótica, Fabbri (2011a) atiende a la relación entre depredador y presa, que exige de ambos un mutuo conocimiento y casi complicidad, constante manipulación de los signos y reversibilidad de las funciones: el depredador se disfraza de presa y viceversa.

La dependencia mutua de los enemigos era ya una evidencia para Clausewitz, que advirtió que "mientras no he derrotado al adversario, tengo que temer que me derrote, no soy por tanto dueño de mí mismo, sino que él me marca la ley igual que yo se la marco a él" (Clausewitz, 2005: 20). Sin embargo, Jullien (1999) interpreta que el gran teórico occidental de la guerra sigue creyendo en la acción como único medio para lograr un objetivo, lo que le impide ver otras opciones más eficaces, esas que el filósofo francés admira en los teóricos chinos: en lugar del heroísmo y la audacia enfrentados a circunstancias contrarias, vale más cultivar en provecho propio el desarrollo natural de los acontecimientos incluso antes de que una potencial confrontación se haga perceptible. No es posible forzar a una planta a crecer a base de tirar de sus hojas con los dedos, pero uno puede mejorar las condiciones del suelo en que se ha plantado la semilla (Jullien, 1999: 146). Del mismo modo, el enfrentamiento más eficaz será aquel que uno ha sabido cuidar desde el principio, y así "la mejor estrategia consiste en atacar al adversario apenas empieza a concebir su propia estrategia; luego, la de atacarlo en sus 'alianzas' (o cuando 'los ejércitos se unen'); luego, en sus 'tropas', y, por último, en sus 'plazas'” (Jullien, 1999: 194). Cada una de esas fases supone el fracaso de las precedentes, pero todas tienen en común una preferencia sistemática por la mentira en lugar de la violencia.

Indudablemente, los conflictos son un lugar de encuentro para 
fenómenos como la sospecha, la intuición, el estereotipo, la amenaza, el chantaje, el engaño, la traición, la subversión de las convenciones o el error. Situaciones en que predominan la astucia, el secreto o la mentira, cuya posibilidad es para Eco (2000: 22) la garantía de la semiosis. Entonces, la generación del sentido puede esconderse en la manipulación de la fuente o del canal, así como bajo ficciones que finjan la presencia del emisor o que impliquen potenciales receptores, o incluso en la generación de nuevos códigos o en la anulación de los antiguos. En resumen, la argucia puede convertir los elementos de la comunicación en piezas de otro modelo en el que los significados se vean modificados.

Como ocurre con los malentendidos o las situaciones cómicas, la comunicación no se ordena en los paradigmas tradicionalmente estudiados (como los elementos de Jakobson), sino que surge en las interfaces entre ellos, donde precisamente la confusión puede llegar a ser el medio irreemplazable para subvertir las certezas del enemigo ${ }^{1}$.

A partir de la naturaleza cultural de la guerra, nos aproximaremos a las posibilidades semióticas del engaño en el conflicto para analizar distintas posibilidades de subversión de los elementos involucrados en la comunicación.

\section{GUERRA Y CULTURA}

Si un conflicto surge en el momento en que los intereses de dos o más partes dejan de ser compatibles (lo que marca el final de la cooperación), el objetivo de cada parte será lograr que la otra renuncie a los suyos y se someta o consienta. Para lograr ese objetivo, es provechoso hacer el esfuerzo de imaginar el sistema de preferencias del enemigo, primero para conseguir que renuncie de buena gana a lo que le favorece (si podemos

\footnotetext{
${ }^{1}$ No se trata aquí de sistematizar los problemas éticos que suscita el conflicto, ni siquiera los de la astucia, sino solo utilizarlo como fuente de ejemplos para un asunto semiótico: más allá de las miserias que acompañan a toda guerra, el recurso al engaño supone tanto la deslealtad de una parte como la ingenuidad de la otra.
} 
conseguirlo mediante la diplomacia) y luego para darle a entender que tiene más que perder si se decide a mantener la confrontación. Aunque muchos ejemplos históricos se acerquen más a la irresponsabilidad de grandes incompetentes (Regan, 2007), lo cierto es que la sorpresa y el engaño son cruciales en el conflicto y en la guerra, y lo han sido en grado creciente con el progreso de los medios tecnológicos que permiten acercarse artificialmente a la situación del enemigo en tiempo real: conocimiento de los elementos que van a entrar en juego, capacidad de comunicarse dentro de un grupo y de acceder a las comunicaciones del enemigo. Si en la guerra neolítica o medieval era imposible trascender el ámbito de alcance de la vista y el oído, una gran cantidad de dispositivos permite hoy una percepción ampliada, lo que supone también la ampliación de los ámbitos del engaño, la simulación y la disimulación. Frente al reducido y esquemático microcosmos de una partida de ajedrez, en que todas las piezas están siempre a la vista de ambos jugadores, el engaño puede adueñarse de una situación de la realidad cotidiana o de la guerra, que Clausewitz (2005: 29) consideraba el terreno privilegiado de la incertidumbre y el azar. Y dado que la diplomacia está cargada de astucias desde antes del inicio de la violencia, la restauración de la paz puede exigir una enorme cantidad de redundancia para probar las buenas intenciones de los enemigos, como se vio al final de la Guerra Fría.

Si todo esto trasciende las dimensiones de la psicología y requiere una explicación semiótica es fundamentalmente porque, a partir del momento en que se desata el conflicto y empieza la partida, no encontramos ya individuos aislados sino sujetos definidos por su posición frente a los otros (Fabbri y Montanari, 2007), participantes en un juego sistemático de convenciones, algunas de las cuales pueden romperse para obligar a la creación de otras nuevas.

Desde luego, los participantes en un conflicto nunca dejan de lado las convenciones que rigen su pensamiento, que inmediatamente se ponen a prueba al enfrentarse a las del adversario. No todo vale en la guerra, entre otras cosas porque nadie es capaz de imaginarlo todo, pero también porque 
muchas de las cosas imaginadas resultan inaceptables, sea por razones humanitarias, deportivas, rituales o simplemente cotidianas. Aunque a veces la sensación de impunidad o la prioridad del éxito lleve a algunos a realizar atrocidades condenadas por su propia cultura, los comportamientos humanos siempre circulan por los caminos semióticamente ordenados de la semiosfera, ese sistema que organiza los fenómenos y sus sentidos y los posibilita por la relación que establece entre ellos: "un fenómeno puede convertirse en portador de un significado (signo) sólo a condición de que entre a formar parte de un sistema y, por tanto, establezca una relación con un no-signo o con otro signo" (Lotman, 1979: 43). En la relación con lo desconocido, con el azar y lo imprevisto que caracterizan la naturaleza viva del conflicto, el individuo recurre sistemáticamente a los patrones aprendidos, que lo obligan "a interpretar como estructuras fenómenos cuya estructuralidad, en el mejor de los casos, no es evidente" (Lotman, 1979: 70). Una semiosfera es un espacio limitado y opuesto a todo aquello que le es ajeno (la "no-cultura"), pero todo texto procedente de otras semióticas o incluso aquello que no procede de ninguna semiótica puede ser traducido y semiotizado para integrarse en ella (Lotman, 1996: 24).

Por otro lado, toda semiosfera está sujeta al cambio, y los códigos de valores militares, se transforman como los demás a través del espacio o del tiempo. Como estudia ampliamente Keegan (1995), las culturas viven transformaciones en relación con lo que es válido en la guerra. Algunas, como los aztecas que conocieron los invasores españoles o los egipcios hasta el fin del Imperio Medio, han desarrollado rituales de combate cada vez menos cruentos que les permitían dirimir sus conflictos internos con un gasto mínimo de esfuerzo y vidas, mientras que otras, o las mismas en otros momentos, renunciaron a las posibilidades simbólicas para imponer por la violencia su voluntad (los hoplitas griegos, los guerreros de la estepa). Obviamente, cuando se da un desequilibrio entre las mentalidades de dos grupos culturales que entran en conflicto, eso puede suponer el desastre para quien detenta unas convenciones simbólicas. La semiosfera ya no puede ignorar esos alotextos y debe traducirlos para integrarlos, lo que 
transforma también su propio sistema. Igual que los ingleses condenaban la poca deportividad de los bóers, que escapaban a lomos de sus ponis en lugar de contener el ataque, muchos grupos étnicos invadidos por tropas coloniales sufrieron su falta de respeto por convenciones guerreras que ellos consideraban sagradas. Si los antiguos egipcios tuvieron la ocasión de adaptarse a la guerra cruenta gracias a que las amenazas procedentes del delta del Nilo no fueron demasiado extendidas, los aztecas sucumbieron a unos planteamientos que les eran completamente extraños y que no admitían componendas de ningún tipo.

Clausewitz es el teórico de la opción de llevar la violencia a un extremo de efectividad en el espacio y el tiempo para lograr todos los objetivos con un mínimo gasto, pues "aquel que se sirve de la violencia sin reparar en sangre tendrá que tener ventaja si el adversario no lo hace" (Clausewitz, 2005: 18), concepción que seguramente estaba en germen en el ideario ilustrado de razón y progreso.

Keegan (1995: 32-44) sugiere que esa idea es la que ha llevado a la guerra total, haciendo que, durante un periodo de tiempo al menos, todo haya sido legitimado en aras de la consecución de unos fines políticos, sea la revolución, el nacionalismo, el progreso, la independencia frente a las metrópolis, etc. La escalada del todo vale podría haber empezado en la guerra franco-prusiana, habría llevado a la guerra de producción y desgaste de 1914, y habría justificado teóricamente los ataques sin declaración y las sistemáticas violaciones de las convenciones en la Segunda Guerra Mundial. Pero si la bomba atómica puede ser el momento de máxima perfección de la teoría, el peligro nuclear de una destrucción planetaria, en cambio, impuso la necesidad de unas nuevas normas. Precisamente, Fabbri y Montanari (2007) señalan el advenimiento de la semio-guerra y de la "gesticulación" a partir del momento en que la guerra física resultaba impotente frente al peligro de destrucción mundial y se volvía necesario ocuparse no de la guerra sino de su virtualidad: la política exterior reciente de Irán o de Corea del Norte es un ejemplo más de la eficacia de tal gesticulación. A su vez, las convenciones de Ginebra no son un universal, 
sino una muestra de las limitaciones culturales de la guerra, un ejemplo de normatividad, de lenguaje de la guerra.

A veces la convención se esconde donde no se pensaría. Desde luego, el progreso de los medios de comunicación ha hecho que (aparte de constituirse en una clase más de armamento) las posibilidades de llevar la violencia al extremo se vean limitadas por lo que es "humanitario". En el mundo globalizado, los gobiernos tienen que satisfacer las conciencias de sus ciudadanos e incluso deben someterse a los criterios de la opinión pública extranjera: si a menudo son capaces de manipularlos, deben mantenerse dentro de unos límites, contentando a determinados intereses privados mientras puedan presentarse como guardianes de la civilización frente a la barbarie. Ya en la Segunda Guerra Mundial, mientras Hitler se permitía saltarse las convenciones internacionales, los aliados no siempre se vieron legitimados para hacerlo.

$\mathrm{Y}$ es que los militares no se limitan (como los jugadores) a derrotar al enemigo, sino que tienen que convencer a quienes los sustentan — sus civiles - de que merecen la victoria. Incluso pueden necesitar (por razones de logística) la ayuda de los civiles contrarios. Sin embargo, los extremos de convencionalización de la violencia pueden encontrarse con mayor claridad en los rituales de los guerreros "primitivos", aducidos por Keegan (1995: 116-150), que limitaban el alcance de la guerra o transferían su capacidad resolutiva a enfrentamientos simbólicos. En lugar de llegar al cuerpo a cuerpo, por ejemplo, ciertas etnias de Oceanía se situaban a cierta distancia y se insultaban; un arquero disparaba hacia arriba una flecha que los contrarios debían esquivar antes de responder con otra lanzada de la misma manera. Al primer derramamiento de sangre se daba por concluida la batalla.

Según este autor, la guerra no es la política desarrollada en otro ámbito, como quería Clausewitz, sino "entre otras cosas, la perpetuación de la cultura por sus propios medios" (Keegan, 1995: 71), puesto que "implica mucho más que la política y que siempre es una expresión de cultura, muchas veces un determinante de las formas culturales $\mathrm{y}$, en 
algunas sociedades, la cultura en sí” (Keegan, 1995: 31). Señala por ejemplo la reacción de los samuráis frente a una demostración militar al estilo occidental organizada por Takashima en 1841, considerando el desfile como un juego de niños en oposición a la expresión personal del combate cuerpo a cuerpo (Keegan, 1995: 29).

La ritualización de los elementos agresivos es universal, la encontramos tanto entre las formas de guerra 'primitiva' como en la actual, en que es fundamental el desfile, el uniforme de gala, la marcialidad, el código de comportamiento militar. Lotman habla de hiperestilización en las milicias de la época napoleónica, a lo que Fabbri y Montanari (2007) añaden varios ejemplos de ostentación militar. Por supuesto, el extremo alcanzado en la simbolización de la agresividad puede encontrarse en la representación de la guerra en los medios de comunicación (Baudrillard, 1991).

\section{LA MENTIRA EN LA GUERRA}

La condición cultural de la guerra queda de manifiesto en la multiplicidad de los engaños que consiente. Cualquier momento de la vida está ordenado por sistemas de convenciones, pero estas se vuelven urgentes en la guerra: todo se convierte en signo cuando cualquier cosa puede darnos una indicación valiosa sobre nuestras posibilidades de conseguir nuestros objetivos y sobre el peligro que corremos. Como señala Fabbri (2011b) nadie piensa tanto en los otros, en sus planes e intenciones, como en tiempo de guerra.

El mismo recurso a la amenaza de violencia es un acto semiótico:

Si el adversario ha de hacer nuestra voluntad, tenemos que ponerlo en una situación más desventajosa que la del sacrificio que exigimos de él; pero naturalmente las desventajas de esa situación no deben ser pasajeras, al menos en apariencia, porque de lo contrario el adversario esperará un momento mejor y no 
cederá (Clausewitz, 2005: 19).

Esta manipulación que está en el punto de partida de todo enfrentamiento violento pone en marcha todo un juego de desequilibrios más o menos controlados por parte de ambos contendientes, y empieza en la fase, todavía diplomática, de la amenaza.

El primer elemento que se puede fingir es la intención. Hacer creer al otro que estamos dispuestos a llevar a cabo determinada acción puede lograr el objetivo de provocar en él una respuesta que nos interesa. En juegos como el ajedrez o el fútbol esta parece ser la única posibilidad de engaño, la insinuación de un futuro camino que estamos pensando en realizar, pero es algo obviamente posible en todo tipo de conflictos reales. Una posición concreta es un signo que está en lugar de de un desarrollo potencial. Mostramos fortaleza para disuadir al otro de perjudicarnos.

La intención puede asumir también una apariencia negativa. Ocultamos, disimulamos aquellos elementos de la realidad que puedan delatar nuestra intención o nuestra capacidad de realizar la acción: camuflamos nuestros ejércitos, disimulamos nuestras gestiones para lograr un efecto sorpresa y una inadecuada reacción por parte de los potenciales perjudicados.

A partir de ahí, el ingenio humano se ha aplicado con especial intensidad en las situaciones de gran riesgo y promesas de ganancia, unas veces con éxito y otras con una ingenuidad poco acorde con la complejidad de la realidad. Como detalla Fussell (2003: 36), "las 'ideas militares brillantes' tienen la costumbre de terminar de manera desastrosa", y muchas veces su éxito se debe menos a su verdadera adecuación que a cualquier circunstancia incontrolada que favorece a unos y destruye a los otros.

También Clausewitz desconfía de la verdadera utilidad de la astucia: "[...] es peligroso emplear fuerzas importantes durante largo tiempo con fines de mera apariencia porque siempre existe el peligro de que se haga en vano y se prescinda de esas fuerzas en el lugar decisivo" (Clausewitz, 
2005: 169).

En realidad, frente a algunos pocos casos de correcta percepción de la realidad que ha podido ser aprovechada para lograr una clara ventaja en un momento dado, la historia aparece llena de errores y de apreciaciones equivocadas tanto por parte de los vencidos como de quienes resultaron vencedores. La mayor parte de las veces, una vez desatada la violencia, el triunfo parece estar de parte de quien tiene ventajas de otro tipo (numérica, armamentística, logística, moral, etc.), pero los engaños forman parte del lenguaje mismo de la guerra, y como tales han sido analizados repetidamente al menos desde los tiempos de Sun Tzu. La astucia reaparece a distintos niveles para alcanzar ventajas parciales.

Fabbri (2011a) señala — respecto al mundo animal — que no importa tanto lograr un engaño definitivo como una táctica del contrapié, forzar al antagonista a la indecisión el tiempo necesario para obtener una ventaja. Así, cuando el tigre ve unos grandes ojos en la grupa de su presa y espera que su movimiento sea en ese sentido, basta un instante de indecisión para concederle a esta un plazo que le permita ponerse a salvo.

\section{IDENTIDADES Y RESTRICCIÓN}

En general, encontramos semiosis cuando cualquier rasgo o fenómeno se percibe como portador de una información diferente; y este es engañoso cuando esa información no se verifica en la realidad.

Una identidad resulta reconocida y parece incompatible con cierto conjunto de alternativas incluidas en la parte desconocida de la realidad (fundamentalmente, las posibilidades e intenciones del enemigo), mientras que un haz de alternativas resulta posible, compatible con el nuevo dato. Lo ignorado se ordena en conjuntos de fenómenos posibles condicionados entre sí, de modo que la aparición (fingida o verdadera) de uno de ellos condiciona en la mente que lo interpreta la exclusión de todos aquellos en que este no sería posible. Se trata de una forma de restricción semántica por etapas: cada identidad nueva que se combina con lo conocido provoca 
una restricción de variantes incompatibles con ella; cuando acumulamos las suficientes, podemos llegar a asumir una determinada interpretación suficientemente satisfactoria y decidirnos por una respuesta práctica. $\mathrm{O}$ pueden aparecer nuevos datos contradictorios con esa interpretación, tal vez demasiado tarde.

Podemos volver a Eco para definir estas identidades tal como aparecen fuera de los lenguajes más formalizados que estamos acostumbrados a estudiar, como las lenguas naturales. Para él, "en todas las culturas una unidad cultural es simplemente algo que esa cultura ha definido como unidad distinta de otras $y$, por lo tanto, puede ser una persona, una localidad geográfica, una cosa, un sentimiento, una esperanza, una idea, una alucinación" (Eco, 2000: 112). Eco recurre al concepto de unidad cultural para entender el significado de cualquier término en el entorno de los interpretantes de Peirce: el signo remite a otro signo, su interpretante, pero "el interpretante de un signo no tiene por qué ser un signo del mismo tipo (perteneciente al mismo sistema semiótico)" (Eco, 2000: 187). O sea que un signo remite a otro, una palabra a una imagen, o a un olor, o a una idea de otro tipo, etc. Y la semiosis consiste en la traducción de unas unidades culturales por otras (interpretantes) de una forma más o menos ilimitada, siempre postergable: puesto que "también las ideas son signos" (Eco, 2000: 250), todo interpretante puede remitir todavía a otro interpretante.

En última instancia, podemos definir las "identidades" (que preferimos no llamar "significantes" para evitar sugerir que tengan un significado estable) como elementos que somos capaces de reconocer porque previamente hemos tenido experiencia de algo aproximadamente similar a ellos. Algo que reconocemos, sea natural o artificial, presencia o ausencia, material o imaginario, con lo que operamos para restringir eso a lo que tal vez sustituya.

Combinando esas identidades, cuyas funciones semióticas pueden estar estructuradas o jerarquizadas por "hipercodificación” (Eco, 2000: 366), se forman sintagmas, que dan lugar a una compleja sistemática de 
operaciones de restricción a partir del "Universo Semántico Global” (Eco, 2000: 199) o "espacio semántico general” (Eco, 2000: 263), es decir, del plano de lo imaginario.

Igual que la cooperación, la hostilidad lleva a generar signos a partir de los códigos conocidos y de la realidad circundante. Pero mientras que la comprensión mutua promueve un beneficio común a las partes implicadas en la cooperación, un contendiente saca ventaja sobre todo de la posibilidad de que su enemigo se equivoque, sea por incompetencia natural o como consecuencia de sus añagazas.

Una identidad puede cambiar de posición y de función en el marco de modelos comunicativos diferentes.

\section{ELEMENTOS DESPLAZADOS}

En el marco de un modelo comunicativo como el del habla, estas identidades son equiparables a los significantes lingüísticos. Del mismo modo que en la lengua las palabras conforman frases que conforman textos, en la guerra los movimientos conforman tácticas que conforman estrategias (Fabbri, 2011b). Al menos en el sentido de esta "doble articulación", efectivamente, hay un paralelo: unidades significantes menores se articulan en unidades mayores.

Sin embargo, en el estudio de la lengua es fácil establecer un límite entre los enunciados lingüísticos (mensaje) y los demás elementos: las circunstancias, siempre fuera del sistema que las traduce; el código gramatical, valedor externo (langue) que no se confunde con el mensaje (parole); el canal; emisor y receptor. Queda fuera del interés de los lingüistas la consideración de que esos elementos puedan asumir funciones sígnicas en otros modelos.

Sin embargo, la flexibilidad y elasticidad de los tantas veces violados códigos militares implica un material semiótico en el que se confunden los elementos de la comunicación: códigos y circunstancias con los que se ordenan y relacionan los textos, participantes no siempre 
voluntarios (emisor y receptor), canales entremezclados, etc.

Van Dijk (2012: 50) prefiere considerar el contex to como "un modelo mental específico, o una interpretación subjetiva, de los participantes de las propiedades relevantes (sociales, interaccionales o comunicativas) de la situación en la que participan". Desde un punto de vista semiótico, sin embargo, esas estructuras que el individuo va edificando en la memoria se acercan peligrosamente a la idea de código, como conjunto de normas que permiten la interacción con la realidad. Para van Dijk basta con tener claro que no forman parte del código lingüístico, por lo que tienen que estar en otro ámbito, el de la formalización de las circunstancias, o sea el contexto. Eco llamaba "contexto" de un elemento concreto a los elementos del mismo código que pueden combinarse con él, y "cotexto" a otros elementos efectivamente combinados en un mismo texto (Eco, 1993: 29), planteando la realidad circundante como "circunstancias" que entran en el universo semiótico por medio de "unidades culturales". La diferencia puede no ser tan grande si asimilamos las unidades culturales de uno con los modelos mentales del otro.

La distinción entre contexto y discurso, cuyos límites trata de establecer van Dijk (2012: 51), flaquea cuando abandonamos esos códigos tan sofisticados y exclusivos que son las lenguas naturales. La guerra nos sirve para establecer que, si las ideas son signos y las unidades culturales también pueden serlo, no hay diferencia sustancial entre mensaje, código, circunstancias, canal y actores, elementos que participan polifacéticamente en la semiosis.

Las identidades serán simplemente aquellas porciones de la realidad que resultan susceptibles de reconocimiento (en virtud de una serie de oposiciones que las convierten en haces de rasgos diferenciados, como proponían los estructuralistas) y por lo tanto de incorporación a un código (al relacionarse con una porción determinada del plano semántico). Pero tales identidades no son exclusivas de la realidad material ni dependen de la voluntad de un emisor ni de la percepción de un receptor, sino que pueden aparecer también en forma de ideas (código) o percibirse como 
circunstancias azarosas, o asimilarse al canal que las transmite. En estos casos, elementos procedentes del código o de las circunstancias pueden pasar a conformar "textos" y "hablar" a un receptor avisado o ingenuo.

Las circunstancias son materia informe en la que el sujeto identifica formas ajenas al mensaje en las que el mensaje sitúa su referente. Pero esas formas ajenas pueden investirse en signos en virtud de alguna asociación a un nuevo código que pasa a ser pertinente. Esa transformación se debe a un acto interpretativo que puede, sin embargo, haber sido inducido: hacemos que el enemigo vea e interprete circunstancias ocultándole la manipulación, como cuando se imitan las huellas de un número superior de efectivos, o se finge una logística desmesurada. Eco (2000: 171) reconoce que las circunstancias también están codificadas: obviamente no han sido construidas a partir de un código como las palabras son generadas por un hablante que conoce la lengua, pero solo pueden ser comprendidas, solo pueden generar una respuesta cuando han pasado por la criba de los códigos: "de ese modo, las selecciones contextuales y circunstanciales no requieren un tipo de instrucción particular, porque también ellas son unidades culturales".

Para hacernos una idea de la importancia que tienen los códigos en la historia de la guerra, podemos considerar aquellos casos en que los militares han ignorado todas las evidencias presentes y se han dejado llevar por estereotipos y prejuicios. En la batalla de Créçy, pese a derrotas previas similares, los franceses siguieron una línea de batalla conservadora a base de un avance frontal de la caballería pesada que fue destruida por los arqueros ingleses (Regan, 2001: 63-67). El código de la guerra feudal les impidió ver las evidencias de una novedad anunciada. Lo que estuvo en lugar de otra cosa no fue un objeto físico de la realidad, porque todos estos apuntaban a la necesidad de buscar una nueva interpretación, sino una idea previa considerada universal. Elementos surgidos directamente del código son capaces de llevarnos a conclusiones falsas: al que tiene un martillo en la mano todo se le hacen clavos.

Al contrario, la ausencia de un código puede impedir que 
identifiquemos una entidad: pese a las evidencias mostradas por imágenes aéreas en Peenemünde en 1943, los mandos británicos no fueron capaces de identificar los cohetes A-4 porque no sospechaban que pudieran tener forma circular vistos desde arriba, ni que pudieran lanzarse desde una plataforma portátil (Keegan, 2012: 323-324).

Respecto al canal, sin ánimo de jugar con McLuhan, podemos decir que puede ser un mensaje si la propia utilización de ese canal constituye una novedad portadora de sentido: la mera utilización de la radio podía delatar la presencia de un barco en el contexto de la Gran Guerra.

Naturalmente, tampoco están ausentes de las operaciones militares los signos tradicionalmente considerados, como las palabras que se usan para comunicaciones entre aliados y entre adversarios, desafíos, ultimátums, amenazas, promesas, etc., o los códigos de galones para simbolizar las posiciones en la cadena de mando.

Hay que entender que ninguno de los elementos aparece aislado: los signos cooperativos se comunican por un canal hacia un receptor y se disponen en unas circunstancias, de acuerdo con unos códigos; las argucias se valen de ese complejo mundo para subvertirlo de manera inadvertida y ventajosa.

\subsection{Circunstancias}

Una gran parte de los engaños militares consiste en fingir circunstancias, es decir en tratar de hacer pasar por naturales los elementos que en realidad han sido puestos ahí para generar una interpretación falsa por parte del adversario. Y lo contrario: hacer pasar por signo lo que originalmente era circunstancia. Signo y no-signo, o identidad y circunstancia, intercambian sus credenciales, merced a la flexibilidad o fragilidad de los códigos que permiten identificar identidades entre las circunstancias. Jullien se interesa por el análisis que hacen los pensadores chinos sobre la explotación de las circunstancias: 
[...], lo circunstancial ya no se concibe solo -incluso ya no se concibe en absoluto - como lo que "está alrededor" (circumstare), como algo accesorio o un detalle (que acompaña lo que sería lo esencial de la situación o del acontecimiento y remite por ende a una metafísica de la esencia); sino que es aquello a través de lo cual se produce el potencial, precisamente, como potencial de la situación (Jullien, 1999: 48).

Se distinguen varias posibilidades teóricas.

La ocultación (cripsis) consiste en volver imperceptible algo que tendría un significado para el enemigo en caso de descubrirlo: enterrar objetos, esconderlos tras la pendiente o tras objetos cotidianos, generar pantallas de humo, etc. (Marín, 2004: 93-94).

Por el mimetismo, se intenta conseguir la asemiosis, o mejor aún la inexistencia (en la semiosfera del otro) por medio de la confusión entre las circunstancias: todo lo que se disimula, se finge civil, árbol, etc. pretende no ser unidad cultural para el otro, o bien que la cosa que nos delata (la "firma") no lo sea. Así, el sistema de los significantes se queda sin unidad a la que asignar un significado. El animal camuflado evita ser reconocido porque así aumentan sus posibilidades de supervivencia. El objeto se oculta, el signo desaparece, la unidad cultural se difumina en el continuum.

Como todo secreto, ocultación y camuflaje sirven para que uno evite ser "señalado como singular por una singular diferencia y que de esta manera en el origen, un gesto primitivo [...] lo marcara con una única diferencia" (Marin, 2012: 14).

El camuflaje consiste en difuminar en lo posible las diferencias, el "haz de rasgos opuestos" en que puede analizarse y descomponerse la identidad, para que el código de que dispone alguien (el receptor del ruido) sea incapaz de identificarlo. Eso posibilita una presencia no inmediatamente significante pero virtualmente significante: capaz de agredir. El método consiste en un cuidadoso retorno al continuum, a partir de un estudio de este que permita anular las diferencias y contrastes entre 
el objeto virtualmente identificable y las circunstancias.

Mejor decir entonces que hay secreto si al menos una identidad diferenciada para alguno de los actores que participan en un sistema de funciones semióticas pasa a desdiferenciarse artificialmente para otros actores. Con su desaparición funcional, pierde su capacidad de combinación con otras identidades.

En el caso del disfraz, la identidad desaparece bajo una forma diferenciada pero que asume otra función (inofensiva) para el código. Centrado en la zoosemiótica, Fabbri distingue camuflaje para pasar desapercibido y camuflaje para asustar. En la guerra encontramos ejemplos de los dos: al pintar de alquitrán la dorada cúpula de San Isaac en Leningrado se trataba de hacerla pasar desapercibida para protegerla. Lo segundo se basa en buscar un efecto disuasorio, pretende evitar el ataque de fuerzas superiores haciendo que se crean inferiores: como el gato que se eriza para parecer mayor, Baden-Powell en Mafeking desplegó todo un sistema de defensas ficticias para evitar que los bóers llevasen a cabo un ataque directo (Marín, 2004: 69-71). Cañones, aeródromos y tanques fraudulentos se han usado en todas las guerras del siglo Xx.

Es cierto que otra forma de camuflaje pretende no tanto pasar desapercibido como dificultar la localización exacta por medio de dibujos confusos, pretensión de disruptive patterns como el del tigre, que rompe la silueta del animal o del objeto: en este caso, lo que se desdiferencia no es el conjunto de la identidad, que acepta ser reconocida, sino alguno de sus rasgos, su forma, sus límites.

Todos los objetos circunstantes pueden ser usados para la desdiferenciación, lo que podría llamarse "bricolaje" en honor a LéviStrauss (Fabbri, 2011a). Como el cangrejo ermitaño, podemos recordar la utilización de barcos mercantes para el transporte de los misiles de la URSS a Cuba en la operación Anádir, o la de edificios civiles por el ejército serbio para esconder material militar durante los bombardeos de la OTAN (Marín, 2004: 307-316).

La primera variedad de camuflaje desdiferencia una unidad cultural 
en el continuum: el guerrero desaparece entre la hojarasca, y su enemigo no identifica nada en el bosque. Otra variedad desdiferencia la unidad cultural para asimilarla a otras unidades culturales; se inducen traducciones interesadas entre sistemas de la semiosfera: un árbol falso usado como puesto de vigilancia en el frente es un caso de unidad cultural ambigua.

Encontramos otra forma más de mímesis en los señuelos: se utiliza un objeto para que pase por otro y atraiga la atención del enemigo con varios posibles resultados favorables. La primera posibilidad es que el enemigo malgaste sus fuerzas contra un objetivo ilusorio, causando un desperdicio de munición y esfuerzos: como los falsos aeródromos ingleses que la Luftwaffe bombardeó durante la batalla de Inglaterra. O provoca la concentración sobre un objetivo falso librando temporalmente de atención al verdadero: como el ataque al norte de Bélgica en la estrategia alemana de la Batalla de Francia (1940), una distracción del verdadero objetivo de atravesar las Ardenas, al sur. Otra posibilidad es tender una trampa, atraer al enemigo a una situación de falsa superioridad, astucia ya considerada en las guerras antiguas y que viene descrita por el emperador Mauricio en el Strategikon: la deliberada debilidad del ala derecha de Napoleón en Austerlitz logró atraer a las fuerzas aliadas a una posición de debilidad, fuera de las posiciones fuertes de los Altos Pratzen. Pero un señuelo puede ser clave para identificar la posición del enemigo, como las llamaradas de cañones soviéticos aislados en una falsa posición que atrajeron el fuego alemán a través de la pantalla de humo a lo largo del Oder para localizarlo y neutralizarlo (Marín, 2004: 240).

La unidad cultural reconocida puede tener por interpretante un arma, o un ser humano, o un elemento que a su vez tenga como interpretante al ser humano. Troncos pasan por cañones; aviones pintados en el suelo simulan aeropuertos; lanzaderas de misiles de plástico; tanques de cartón; maniquíes; excrementos de caballería que hacen creer al enemigo en la presencia de un gran ejército.

Hay otras posibilidades. La sustitución consiste en fingir que se mantiene una situación cuando en realidad algo ha cambiado: para ello es 
necesario que se produzcan ciertos cambios. Por ejemplo, un ejército se retira pero lo hace durante la noche y dejando en su lugar señuelos, como hizo Aníbal poniendo antorchas en los cuernos de la ganadería mientras huía (Marín, 2004: 51).

Otros engaños requieren más elaboración: es posible hacer llegar a manos del enemigo nuestro falso plan para condicionarlo. Se puede fingir un error o una filtración, o adular al enemigo haciéndole creer que ha obtenido la información por su propia sagacidad, o simplemente hacerle creer que es un caso de mala suerte. El caso más relatado es seguramente la operación Mincemeat (Marín, 2004: 187-216), por la que en 1943 los aliados hicieron llegar a los alemanes el plan de invasión de Cerdeña que debía distraer una buena cantidad de efectivos de Sicilia, verdadero objetivo aliado. Los detalles del engaño (la biografía ficticia de un ahogado que apareció en una playa de Huelva) se prepararon de manera extremadamente cuidadosa, lo que lo ha convertido en objeto privilegiado de la literatura y el cine.

Es interesante constatar que hay casos inversos, en que pasa por engaño lo que en realidad es un error, como el incidente Mechelen: el comandante Reinberger, portador de los verdaderos planes de invasión de Bélgica y Holanda, fue capturado en Bélgica tras un aterrizaje forzoso en 1940, de forma tan inverosímil que los mandos franceses no llegaron a descartar que fuera una falsificación (Marín, 2004: 40). Se trata entonces de un caso de semiosis por hiperinterpretación, puesto que los franceses habrían visto algo que no estaba allí en lugar de ver lo que sí estaba.

\subsection{Códigos}

Ya hemos prestado atención a los códigos explícitos, convenciones que definen los límites de la guerra y sus funciones aceptables para una sociedad, incluyendo los mencionados ritos guerreros incruentos. Pero también hay códigos menos explícitos que encauzan las vidas y costumbres de los individuos y grupos que participan en las guerras: maneras de relacionarse entre las personas o con el medio, conocimientos 
y presupuestos, generalizaciones, ideas fijas, concepciones generales de la vida, formas de pensar. Muchos comportamientos humanos se ven modificados en tiempos de guerra, cuando es necesario aprender a afrontar realidades nuevas, a menudo mucho más difíciles que las propias de la vida cotidiana: los individuos desarrollan sus ideas comunes para adaptarlas a la nueva situación y ser así capaces de relacionarse con ella de manera eficaz y equilibrada (Fussell, 2003).

Algunas de estas maneras de ver o hacer, o de gestionar el entorno, no implican necesariamente la codificación de un contenido, es decir que, aunque sean convencionales y respondan a sistemas ordenados de normas, no aparecen "en lugar de" otras cosas, ni restringen las posibilidades interpretativas. Se trata de elementos semióticos sistematizados por los humanos pero que no implican por completo la correspondencia de un plano sintáctico y otro semántico, entre los que podemos incluir todo lo que "se hace as'́n": en la vida civil, podemos ejemplificarlo con gestos culinarios innecesarios pero recurrentes; en el ambiente militar, algunos protocolos y formas de la disciplina.

Los grupos humanos se diferencian al enfrentarse con realidades físicas comunes según distintos patrones de comportamiento. A veces esas costumbres tienen relación directa con el grado de beneficio en la explotación de los medios naturales, como la manera de tratar a los animales de carga, o de manejar un determinado armamento, o de relacionarse con la población local, o de cruzar un río (y la previsión de sus consecuencias podría considerarse el "significado" de las acciones). En los enfrentamientos entre galeones y galeras, las segundas podían aprovechar su ventaja en situaciones de calma chicha, cuando los galeones quedaban inmovilizados. Sin embargo, con frecuencia el ser humano prefiere actuar de un modo específico por mera costumbre, sin beneficio ni perjuicio. Sun Tzu, tan atento en otras ocasiones a las posibilidades de la astucia, recomienda inequívocamente observar unos modos de comportamiento sorprendentemente rígidos en la relación de un ejército con las condiciones naturales. 
Como s-códigos (Eco, 2000: 67-70), esos modos de hacer pasan a relacionarse con un sistema semántico para un adversario capaz de advertir su sistematicidad y de utilizarla en su favor. Siempre puede convertirse una estructura sistemática completa en s-código de un nuevo sistema semántico. Como advertía un panfleto del Departamento de Guerra británico en 1941, los alemanes podían fingirse ingleses para espiar: "Se deberá [...] recalcar a todas las tropas que el uso en la conversación de 'f---s' y 'b----s' no es necesariamente una garantía de la nacionalidad británica" (Fussell, 2003: 122). De este modo, las costumbres, los conocimientos de los individuos involucrados en el conflicto, los protocolos más o menos ritualizados, la deportividad en la guerra, los pactos y las convenciones pueden convertirse en s-códigos de un nuevo código cuando un enemigo sea capaz de darles un sentido aprovechable militarmente.

Nuevamente, estas ideas preconcebidas son elementos que pueden ser involucrados en la función semiótica: el adversario tiene en su cabeza algo que le dice lo que ocurrirá si lleva a cabo una acción. Una identidad (aunque mental, memorística, aprendida) está en lugar de otras posibilidades que prefiere descartar.

Entre las formas de aprovechar los prejuicios del enemigo, podemos recoger el ejemplo del ataque árabe a Israel en la Guerra del Yom Kippur en 1973: los árabes manipularon el concepto que los israelíes tenían sobre ellos, un estereotipo que aseguraba su incapacidad para organizarse y sorprender (Marín, 2004: 281-289). Ese prejuicio constituye una identidad que formaba parte de la memoria de los israelíes. De igual manera, los europeos se han visto lastrados por sus prejuicios en las guerras coloniales, y también la rebelión del gueto de Varsovia tomó ventaja gracias al prejuicio racial de los alemanes que suponía a los judíos incapaces de organizar una rebelión a gran escala.

Cuando se planea un engaño, puede aprovecharse este tipo de ventajas, partiendo de la idea de que siempre será más verosímil para alguien una ficción que sea coherente con sus conceptos del mundo. Sin embargo, muchas veces son los propios engañados los responsables de 
su fe en los estereotipos, sin que su enemigo haya tenido que esforzarse para convencerlos. La mayoría de los casos de incompetencia relatados por Regan (2007) suponen la incompatibilidad reconocida finalmente entre los prejuicios de un militar (al mando, planificador o político) y la realidad. El individuo interpreta las unidades culturales que identifica, las enfrenta con sus ideas previas (según esa gramática aprendida) y restringe las infinitas posibles realidades que pueden esconderse tras todo eso hasta llegar a una o varias hipótesis que tiene que dar por buenas. No solo hay semiosis cuando un enemigo ingenioso decide manipular los estereotipos, sino también siempre que esos estereotipos producen interpretaciones e hipótesis de lo desconocido, lo cual es especialmente visible cuando están en contradicción con los hechos perceptibles.

En 1914, en la batalla de Coronel, los barcos de Von Spee se encontraron con los de Cradock frente a la costa chilena. Los dos intérpretes de la realidad maniobraban a partir de las posibilidades alternativas que les presentaban sus modelos del mundo. Evidentemente, ninguno de ellos valoraba la ventaja con la que contaba su enemigo. Es interesante además que ambos se centrasen un mismo detalle, la posición del sol al atardecer, para relacionarlo con sus estructuras y conocimientos previos y generar un significado. Posiblemente sea responsabilidad del azar el hecho de que uno de los dos acertase.

\subsection{Canales, participantes, mensaje}

Como es fácil suponer, también los canales utilizados pueden convertirse en unidades culturales identificables por un enemigo y delatar una presencia o fingirla. Entre otros posibles ejemplos, toda la guerra de cruceros de la Primera Guerra Mundial estuvo dominada por la dialéctica entre las ventajas de utilizar las comunicaciones inalámbricas y el inconveniente de que tales comunicaciones podían ser detectadas y permitir una localización bastante exacta del origen de la emisión (Keegan, 2012: 123-176). 
A su vez, los participantes en alguna comunicación (emisor y receptor) pueden ser identificados como unidades significantes: es lo normal en los casos de cooperación, cuando nadie pretende ocultarse sino que se participa abiertamente, pero también pueden suponer una información crucial en la adecuada comprensión de la realidad en los casos en que se pretende un engaño.

En el caso del Telegrama Zimmermann se conjugan llamativamente varios de los elementos de la comunicación: en 1917, la Inteligencia Naval Británica interceptó un mensaje que había enviado vía cable submarino el ministro de Exteriores alemán al embajador en Estados Unidos, Bernstorff, utilizando la línea telegráfica de la embajada americana en Berlín para encargarle que convenciera al gobierno de México de que se uniera a ellos en la guerra. El dilema inglés residía en que no podían poner la amenaza en conocimiento de los americanos sin declarar su propia deslealtad, pues habían intervenido ilegítimamente su línea de comunicación. Resolvieron el problema fingiendo que había sido un agente en México, el "señor H”, el que había interceptado otra versión del mismo telegrama (Keegan, 2012: 182-183). Basta este breve resumen para entender la importancia que tiene la identificación del canal utilizado, así como los actores involucrados en la comunicación.

Este ejemplo pone de manifiesto la capacidad del mensaje mismo de asumir a su vez una nueva significación más allá de la original. La opinión pública americana pasó por una fase de incredulidad tras llegar al conocimiento del intento alemán frustrado por el espionaje inglés: existía la sospecha de que el mismo telegrama podía ser una ficción fraudulenta ideada por la inteligencia británica para comprometer los intereses alemanes forzando a los Estados Unidos a intervenir en la guerra europea. Según ese modelo, los ingleses habrían inventado el mensaje para darle un sentido nuevo, connotado de maldad y traición alemana. Por contra, si el mensaje era apócrifo su significado era muy diferente: permitía concluir que la perversidad inglesa inventaba falsos testimonios para su propio beneficio. Pero Zimmermann desmintió caballerosamente esa idea, reconociendo su 
responsabilidad en el asunto.

Aunque estos elementos pueden asumir significados más allá de sus posiciones normales en la comunicación cooperativa, hay que reconocer que participan de la semiosis de una forma más marginal, solo de acuerdo con el principio de Friedman de que cualquier cosa puede significar cualquier cosa (Sherman, 2012). Si es posible idear un código que relacione series de elementos cualesquiera para camuflar un mensaje (Friedman proponía un código binario aplicado a dos tipos de pétalos de flores en un dibujo, o de notas musicales en una partitura, o de individuos que participan en una fotografía de grupo), también es fácil ver que los códigos de la cultura se aplican a cañones y troncos, y también a personas que producen mensajes y a canales que los transmiten. Son más volubles y heterogéneos que el código binario de Sir Francis Bacon que adaptaba Friedman, pero son equiparables desde un punto de vista teórico.

\subsection{Generación de nuevos códigos}

En cambio, ciertos aspectos del código y las circunstancias pueden asumir funciones semióticas merced a ciertas combinaciones: la insensibilización por medio de falsas alarmas no oculta datos pero distorsiona su importancia relativa a partir de la transformación cuidadosa del código por medio precisamente de circunstancias falsificadas.

Un ejemplo de rutina que condiciona la respuesta a un acontecimiento nuevo es la que generaron los continuos bombardeos sobre Berlín, que en diciembre de 1943 hicieron que los alemanes considerasen uno más lo que en realidad era un ataque a Peenemünde, de modo que sus cazas defendieron Berlín dejando desprotegido el verdadero objetivo, los emplazamientos de pruebas de los nuevos cohetes voladores (Marín, 2004: 34-35). Igualmente, las repetidas amenazas terminan por ser ignoradas, como las que orquestaron los mandos egipcios junto a la frontera israelí (y que terminaban siendo meros entrenamientos y maniobras de prueba) antes del ataque sorpresa en la guerra del Yom Kippur (Marín, 2004: 281- 
289).

Otro engaño basado en la creación de un nuevo código forma parte de la operación Cerberus, por la que los acorazados Scharnhorst, Gneisenau y Prinz Eugen lograron cruzar el Canal de la Mancha y volver a los puertos alemanes en 1942. En este contexto, el procedimiento ideado por el general de brigada Wolfgang Martin para burlar los radares consistió en provocar perturbaciones todos los días a la misma hora durante varios días, lo que hizo creer a los ingleses que se trataba de un fenómeno atmosférico y no prestaron atención el día que a esa hora, durante las perturbaciones, los acorazados salieron de Brest y atravesaron el Canal de la Mancha (Marín, 2004: 23).

En este caso, el fenómeno generado artificialmente por los alemanes supuso la sutil programación de un nuevo código, válido solo para los ingleses, que estaba condenado a fracasar en el momento clave. Cada interferencia generada los días previos y a la misma hora fue capaz de codificar una relación entre un significante y un significado (la perturbación y las condiciones atmosféricas). Se trataba de 1) destruir el código cuya extensión era adecuada a la realidad: 'la interferencia en el radar ha podido ser provocada para esconder un movimiento'; 2) generar un nuevo código cuya extensión era inadecuada a la realidad: 'la interferencia corresponde a una perturbación atmosférica'; 3 ) aprovechar el nuevo código inadecuado para actuar sin que el signo sea interpretado correctamente y a tiempo, y generando por tanto una respuesta inadecuada.

Acciones reiterativas como estas vacían de sentido el código previo y sustituyen unos significados por otros. Gracias a esa sustitución, las circunstancias (siempre unidades culturales, eso sí: 'los árabes están haciendo maniobras'; 'hay otra borrasca') asumen un significado inocuo en lugar del significado inquietante.

\subsection{Identidades huérfanas de código}

Los s-códigos se manifiestan en toda su pureza cuando nos 
encontramos con novedades militares cuyo efecto real se desconoce. Cualquiera que no ha asignado un sentido a un tipo (type) será incapaz de identificar adecuadamente el ejemplar (token). Como los naturalistas ingleses que creyeron que el ornitorrinco que estaban analizando tenía que ser la broma de un taxidermista (Eco, 1997: 71), el militar que se enfrenta a un dispositivo novedoso puede perfectamente no saber cómo emplearlo o cómo defenderse de él.

La guerra es ámbito predilecto de las novedades tecnológicas: el ser humano parece siempre dispuesto a aprovechar las posibilidades de cualquier invento para aplicarlo a la violencia sobre los demás. También es uno de los ámbitos en los que tropieza una y otra vez la incompetencia, como recoge Regan: en principio hay que estudiar los ejemplares disponibles y relacionarlos con sus resultados, si es posible imaginando su potencial aun velado, de modo que los dos s-códigos entren en relación para formar un código. Pero muchos militares a lo largo de la historia han resultado incapaces de comprender el código a partir del estudio de las unidades y sus resultados, a menudo porque estaban empeñados en demostrar la perfecta eficacia de lo aprendido en el pasado.

El uso de armamento nuevo implica la ventaja que ese armamento proporciona, a lo que se suma la ignorancia del enemigo sobre las formas de defenderse de él: vale el ejemplo de las bombas volantes de Peenemünde que los ingleses no supieron identificar en sus imágenes aéreas.

Pero el armamento nuevo puede no haber generado tampoco en su usuario o inventor la capacidad de trabajar con él de un modo óptimo: es recurrente el ejemplo del tanque en la primera guerra mundial. La época de entreguerras fue un escenario especialmente dado a especulaciones sobre armas nuevas, unidades culturales a las que ningún código asignaba un significado todavía (Regan, 2007: 100-106). Las novedades introducidas en la Primera Guerra Mundial experimentaron una enorme evolución en los años siguientes, de modo que los significados adquiridos previamente se habían quedado obsoletos. Ante la falta de presupuesto o de posibilidades de utilizar en la práctica esos nuevos modelos, la polémica envolvió todos 
esos avances: había quienes mantenían la eficacia de la caballería, o de la infantería lanzada en masa contra el enemigo (ignorando la superioridad de las ametralladoras); a partir del pánico desatado por los bombardeos con zeppelines, se generalizó la fe en la estrategia de desmoralizar a la población civil mediante bombardeos masivos en retaguardia, que se demostraría tan cruel como ineficaz.

Otra cuestión que generaba polémica era la competencia entre la aviación y el fuego antiaéreo de que eran capaces los acorazados. Solo cuando la aviación japonesa destruyó los modernos cruceros británicos Prince of Wales y Repulse en Malasia resultó patente que ningún barco podía enfrentarse solo a un enemigo que detentase el control del aire (Regan, 2007: 144, 331-349). Que Churchill hubiese considerado que esta era una aportación suficiente para disuadir a los japoneses de un probable ataque a la base de Singapur prueba que fue incapaz de apreciar el valor real de los barcos sin cobertura aérea.

En algunos momentos históricos, incluso, un avance técnico puede llegar a suponer una clara desventaja, si se utiliza frente a unas circunstancias que no permiten explotar sus posibilidades y que sin embargo potencian sus defectos. Las máquinas que Scott llevó al Polo Sur se demostraron menos eficientes en esas condiciones extremas que los tradicionales perros que llevaba Amundsen. El ejército estadounidense empleó en las Lomas de San Juan en 1898 un globo aerostático cuya finalidad era localizar al enemigo, pero que sirvió para que el enemigo tuviera siempre una referencia clara de su posición y pudiera disparar incluso sin ver a los soldados (Regan, 2007: 287).

Hay otro medio por el que el desarrollo de una tecnología de vanguardia puede perjudicar a sus inventores. La incorporación de una novedad es capaz de volver obsoleta toda tecnología anterior, y esto puede perjudicar especialmente al que había invertido más esfuerzo en ese desarrollo obsoleto, especialmente si permite que sus competidores se pongan al día. Este conjunto de circunstancias pudieron darse con la aparición del HMS Dreadnought, un acorazado inglés que revolucionó 
la carrera armamentística en 1906, pero tal vez dio tiempo al Imperio Alemán a ponerse al día y competir en las nuevas circunstancias con la flota británica (Regan, 2007: 95).

\section{CONCLUSIONES}

Si bien todos los aspectos de la vida están envueltos en esa jerarquía de sistemas semióticos que Lotman llamó la semiosfera, los conflictos son capaces de exacerbar nuestra dependencia de las funciones semióticas hasta niveles que no son habituales en las fases de cooperación. Puede ser cierto, como defiende Keegan (2012), que la inteligencia no es condición suficiente para el éxito, sino que hace falta una fuerza real que apoye esa inteligencia, sea en forma de recursos humanos, armamentísticos, de posición, tácticos o morales. La incertidumbre está a la vuelta de todas las esquinas, y el conocimiento de los planes del enemigo puede ser insuficiente, como muestra ese autor con varios ejemplos entre los que destaca la defensa de Creta por los ingleses en 1941, cuando el conocimiento exacto de los planes de la invasión alemana logrado por la descodificación de Enigma no impidió que esta se realizase (Keegan, 2012: 177-222). Otros ejemplos relacionados con el espionaje en los siglos XX y XXI muestran que el avance en los medios tecnológicos no ha implicado necesariamente un mejor aprovechamiento de la inteligencia: los fallos en los bombardeos de Serbia por la OTAN o en la predicción del 11-S, o la controvertida búsqueda de armas de destrucción masiva en Irak cuestionan que el dominio tecnológico pueda garantizar el éxito.

A pesar de ello, la incuestionable dimensión semiótica del conflicto permite atender a ejemplos que quedan al margen de los procesos guiados por la cooperación, en los que la distinción entre el mensaje y los demás elementos de la comunicación no es en absoluto evidente, sino que suponen una cierta continuidad. Un nuevo modelo comunicativo puede superponerse a otros previos, pervirtiendo su orden de manera provisional o definitiva y dando lugar a nuevas ordenaciones en las que ciertas identidades pueden 
asumir o declinar funciones semióticas según perspectivas vacilantes.

Estas consideraciones sugieren la tentadora idea de que la aparición de las funciones semióticas es independiente de los humanos o del mundo físico; más bien se trata de que la condición humana puede asignar un carácter semiótico a cualquier cosa, tanto a lo que rodea al individuo como lo que está en su interior y lo que comparte con los demás.

Cabe decir que las funciones semióticas aparecen de manera más o menos imprevista, más o menos voluntaria, entre actores de la semiosis que no participan en ellas en simetría. Pero hay otros elementos involucrados, no ya en el sentido esquemático de Jakobson que daba cuenta de lo que rodea al mensaje en la comunicación, sino como actores de pleno derecho, generadores de semiosis. Todos ellos generan significación y mentiras, se entrecruzan y se involucran mutuamente en juegos de sentido siempre al borde mismo de lo imperceptible y de lo inimaginable.

\section{REFERENCIAS BIBLIOGRÁFICAS}

BAUDRILLARD, J. (2001). La guerra del Golfo no ha tenido lugar. Barcelona: Anagrama.

CLAUSEWITZ, C. (2005). De la guerra. Madrid: La esfera de los libros.

DIJK, T. A. (2012). Discurso y contexto. Un enfoque sociocognitivo. Barcelona: Gedisa.

ECO, U. (1993). Lector in fabula. Barcelona: Lumen. (1997). Kant e l'ornitorrinco. Milán: Bompiani. (2000). Tratado de semiótica general. Barcelona: Lumen.

FABBRI, P. (2011a). "Semiotica e camouflage". En Falso e falsi. Prospettive teoriche e proposte di analisi, L. Scalabroni (ed.), 11-25. Pisa: Edizioni ETS (también en http://www.paolofabbri.it/ saggi/semiotica_camouflage.html [27/03/2018]). (2011b). "Logistica, la sintassi della guerra". En Alfabeta2 14, 
noviembre 2011 (también en http://www.paolofabbri.it/articoli/ logistica.html [27/03/2018]).

FABBRI, P. y MONTANARI, F. (2007). "Le forme nuove del warfare e la circolazione di modelli fra semiotica, strategica e letteratura spionistica". En Conflitti. Strategie di rappresentazione della guerra nella cultura contemporanea, V. Fortunati, D. Fortezza, M. Ascari (eds.), 249-259. Roma: Meltemi editore (también en http://www. paolofabbri.it/saggi/forme_nuove_warfare.html [27/03/2018]).

FUSSELL, P. (2003). Tiempo de guerra. Conciencia y engaño en la Segunda Guerra Mundial. Madrid: Turner.

GREIMAS, A. J. y COURTÉS, J. (1979). Sémiotique. Dictionnaire raisonné de la théorie du langage. Paris: Hachette.

JULLIEN, F. (1999). Tratado de la eficacia. Madrid: Siruela.

KEEGAN, J. (1995). Historia de la guerra. Barcelona: Planeta. (2012): Inteligencia militar. Conocer al enemigo, de Napoleón a Al Qaeda. Madrid: Turner.

LASKER, E. (2003). Lucha. La Roda: Merán.

LOTMAN, I. (1996). La semiosfera. I. Semiótica de la cultura y del texto. Madrid: Cátedra.

LOTMAN, J. (1979). "El problema del signo y del sistema sígnico en la tipología de la cultura anterior al siglo XX". En Semiótica de la cultura, J. M. Lotman y Escuela de Tartu, 41-66. Madrid: Cátedra.

LOTMAN, J. y USPENSKIJ, B. A. (1979). "Sobre el mecanismo semiótico de la cultura”. En Semiótica de la cultura, J. M. Lotman y Escuela de Tartu, 67-92. Madrid: Cátedra.

MARÍN, F. A. (2004). Engaños de guerra. Las acciones de decepción en los conflictos bélicos. Barcelona: Inédita.

MARIN, L. (2012). "Lógicas del secreto". Revista de Occidente (Madrid: Fundación José Ortega y Gasset), en http://semioticagesc.com/ wp-content/uploads/2013/01/L\%C3\%B3gicas-del-secreto.pdf [27/03/2018].

REGAN, G. (2007). Historia de la incompetencia militar. Barcelona: 
Crítica.

SHERMAN, W. H. (2012). "Cómo hacer que cualquier cosa signifique cualquier cosa”. Revista de Occidente (Madrid: Fundación José Ortega y Gasset).

Recibido el 27 de marzo de 2018.

Aceptado el 13 de julio de 2018. 